\title{
Beware Zombies and Unicorns: Toward Critical Patient and Public Involvement in Health Research in a Neoliberal Context
}

\author{
Mary Madden ${ }^{1 *}$ and Ewen Speed ${ }^{2 *}$ \\ Faculty of Medicine and Health, School of Healthcare, University of Leeds, Leeds, United Kingdom, \\ ${ }^{2}$ School of Health and Human Sciences, University of Essex, Colchester, United Kingdom
}

OPEN ACCESS

Edited by:

Tiago Correia,

ISCTE - University Institute

of Lisbon, Portugal

Reviewed by:

Guido Giarelli,

Magna Græcia University, Italy Maria Berghs,

De Montfort University, United Kingdom

${ }^{*}$ Correspondence: Mary Madden m.t.madden@leeds.ac.uk Ewen Speed

esspeed@essex.ac.uk

Specialty section: This article was submitted to Medical Sociology, a section of the journal

Frontiers in Sociology

Received: 22 February 2017 Accepted: 15 May 2017

Published: 02 June 2017

Citation: Madden M and Speed E (2017) Beware Zombies and Unicorns:

Toward Critical Patient and Public Involvement in Health Research in a Neoliberal Context. Front. Sociol. 2:7. doi: 10.3389/fsoc.2017.00007
Patient and public involvement (PPI) in UK National Health Service (NHS) research has become an imperative in policy and practice. However, lack of clarity on what PPI is (or might be) has given rise to a poorly monitored, complex field of activity, variously framed by the expectations of policy makers, funders, host organizations, researchers, health professionals, individual recruits, volunteers, activists, and third sector organizations. The normative shift toward PPI has taken place within a neoliberal policy context, the implications of which needs to be explicitly considered, particularly after the Brexit referendum which has left policy makers and researchers wondering how to better appeal to a distrustful public subjected to "post-truth" and "dog whistle" politics. This commentary examines the prospects for a more critical approach to PPI which addresses context, is evidence-informed and mindful of persistent inequalities in health outcomes, at a time when models of PPI in NHS health research tend to be conceptually vague, derived from limited clinical and managerial settings, and centered on a construction of the abstract, rational, compliant, and self-managing patient or layperson.

Keywords: patient and public involvement, public participation, evidence-informed health care, health inequalities, neoliberalism

\section{INTRODUCTION}

Patient and public involvement (PPI) in health research can be spontaneous or planned, invited or sponsored, with citizens engaging in a range of ways, from being compliant data gatherers, sources of data or legitimization, to user leaders and makers of challenging theory (Wehling et al., 2015). At its best, PPI may have the potential for increased democratic accountability, for improving health outcomes, and for addressing the social determinants of health, through for example, improved understanding of different cultures of research and engagements with evidence. At its worst, however, PPI runs the risk of being insignificant, tokenistic, and overly managerialist.

As promissory technoscientific innovations change the organization and practices of contemporary biomedicine, health research is becoming an increasingly complex field of patient expectations, financial incentives, and medical-legal concerns. More research and more medicine are not necessarily leading to more health (Godlee, 2015). If the aim of clinical research is to improve patient care, clinical trials should evaluate the outcomes that most reflect real-world settings and concerns (Heneghan et al., 2017). However, most continue to ignore patient-centered outcomes (Ioannidis, 2016). In the light of these concerns, there has been a growing concern to include patients and other 
stakeholders in the health research process (from topic selection through to the dissemination and implementation of results) on the premise that this will produce more trustworthy and useable information, which is more likely to be taken up in health-care practice.

In the US, the Patient-Centered Outcomes Research Institute has been established as an independent non-profit, nongovernmental organization to improve the quality and relevance of evidence available and so aid better-informed health decisions. ${ }^{1}$ The European Patients' Academy (EUPATI) is a pan-European project of the Innovative Medicines Initiative, which works to involve patients in medicines research and development. ${ }^{2}$ EUPATI is led by The European Patients' Forum with partners from patient organizations, universities, not-forprofit organizations, and pharmaceutical companies. In the UK, the non-profit making organization, the James Lind Alliance (JLA), which supports priority setting partnerships of patients, carers, and health-care professionals affected by a health-care condition, has become a partner organization of the National Institute for Health Research (NIHR). ${ }^{3}$ The JLA has its origins in the evidence-informed health-care movement rather than formal National Health Service (NHS) and NIHR PPI policy or patient/service user movements and has had limited engagement with industry in its processes because commercial interests may not align with scientific or public interests. The NIHR itself was created in 2006 and is funded by the Department of Health "to improve the health and wealth of the nation through research" (Department of Health Research and Development Directorate, 2006). INVOLVE, established as "Consumers in Research" in 1996, is funded by the NIHR to support, "active public involvement in NHS, public health and social care research"; in 2015, they headed a strategic review of public involvement in the NIHR (INVOLVE, 2015a).

In the last decade, PPI in UK NHS research has become a requisite condition for securing funding. The involvement imperative has led to an increase in the levels of PPI activity, but it is not yet the case that, "involvement is a mainstream activity that sits alongside other policy and performance requirements in the NHS" (Ocloo and Fulop, 2011; Crowe and Ceinwen, 2016). Furthermore, the empirical evidence-base demonstrating the worth and impact of PPI remains poor, with supporting evidence tending to be descriptive rather than evaluative (Brett et al., 2010; Wilson et al., 2015). Consequently, there is a lack of consensus about what effective PPI in research processes might look like and how to develop and maintain such processes over time. There are many localized case studies examining PPI in research and service delivery but little conclusive evidence about the best (or worst) ways to invoke PPI in research design, research practice, or research commissioning. The extent to which policy support for PPI in health research results in any actual influence on health research agendas also remains unclear (Madden and Morley, 2016).

\footnotetext{
${ }^{1}$ http://www.pcori.org.

${ }^{2}$ https://www.eupati.eu.

${ }^{3}$ http://www.jla.nihr.ac.uk.
}

This commentary is a provocation stemming from a concern that the investment of time and resources in much mainstream UK PPI in applied health research is taking a form of "busywork," i.e., a time-consuming technocratic distraction. Ironically, the notion of the usefully participating, evidence-engaged patient or citizen has become ubiquitous at the same time as ignorance (McGoey, 2012) and "bullshit" (Frankfurt, 2005) have been successfully harnessed as resources in "post-truth" politics. Simultaneously, UK health policy is being subordinated to the demands of the market while socialized health care is subjected to forces of marketization and privatization (Whitfield, 2012). The NHS has been radically reorganized and spending on key determinants of health has fallen as a result of postcrash austerity policies.

\section{THE UK IMPERATIVE FOR PPI}

A recent statement from NHS England on the benefits of patient and public participation in NHS services makes grand claims for the participatory potential of PPI.

We encourage patient and public participation in the NHS, treat them respectfully and put their interests first. This allows us to develop the insight to help us improve outcomes and guarantee no community is left behind or disadvantaged (NHS England, 2015).

These aspirations draw impetus from the need to respond to scandals reported in the Francis (2013) review and Berwick (2013) report. They are laudable, but declarations such as this acknowledge none of the messy history and complexity of PPI and democratic politics or the power imbalances therein. There is no guarantee that participation "per se" improves outcomes or addresses the causes or effects of disadvantage. This statement conflates aims with achievements via the assertion that everyone is treated with respect and that this somehow puts the apparently complementary interests of patients and publics first, without any competing interests from the professions, third sector or even private sector actors, never mind the state.

In terms of the PPI expectations of key UK research bodies, the NHS Health Research Authority (2013) stipulates that by public involvement it means:

.... a range of activities that enable patients and the public to have a say in decisions about the way health research is planned, designed, delivered, developed, evaluated, managed and regulated. It also means where patients and the public are actively involved in the conduct of research studies (p. 12).

Similarly, the NIHR (currently seen as a PPI leader in an international context-INVOLVE, 2014), states that PPI in research is, "an important part of the research that we fund as well as being part of our research commissioning and management processes. We expect researchers to actively involve the public in their research" (National Institute for Health Research, 2015). The 
NIHR clarify that, in talking about the "public," they draw from the definition offered by INVOLVE (2015b) to include, "patients, potential patients, carers, and people who use health and social care services as well as people from organizations that represent people who use services." INVOLVE defines public involvement as research being carried out "with" or "by" members of the public rather than "to," "about," or "for" them.

Researchers applying for NIHR research funding must therefore design PPI strategies into their research proposals, which may variously facilitate the involvement and engagement of the public, patients, potential patients, carers, service users, and representative bodies, in ways that will positively influence some or all of the planning, design, delivery, development, evaluation, management, and regulation of research. Consider the complexity involved in the social relations across this range of actors and the potential range of different vested interests. Consider also the relative degrees of power and influence that different actors might have within and across these groups. As part of review panels for these research bids, the strength of PPI in submitted research proposals is commented on by individuals appointed as lay PPI experts. If the approaches described by researchers are considered weak, there is little room for feedback to applicants about how to improve (Crowe and Ceinwen, 2016). The outcome of this field of self-definition and complexity is a wide range of PPI activity with various models of patients and public as citizens, consumers, partners in their own care and co-researchers, involving a plethora of potentially conflicting values (Gradinger et al., 2015). The problematic conflation and elision of distinctions between patients and the public identified in health-care service decision-making (Fredriksson and Tritter, 2017) requires further investigation in the field of PPI in health research.

All of which raises a question of why, despite this ongoing lack of clarity about its practices, processes, and means of evaluation, has this drive for PPI in UK health research become ubiquitous? The PPI imperative can be seen as part of a wider "participatory shift" in policy which encourages citizens to participate in democratic decision-making by actively contributing as partners, collaborators, and consultees in political processes (Petersen and Lupton, 1996). This mirrors broader international shifts away from models of "government" toward models of "new public governance," informed by a perceived need to address a purported "democratic deficit," as established representative democracies were criticized for failing to match citizens' aspirations for democracy (Norris, 2011). This shift signaled a move from a position that saw involvement, "in relation to people as citizens with rights to receive public services and responsibilities to be involved in their development and accountability," toward a more consumerist model, "in which the relationship is between the layperson and a particular service or organisation" (Taylor, 2007). Moves toward PPI may speak to the perceived democratic deficit, but PPI continues to be so conceptually and theoretically vague that it can mean anything (and nothing) and serve a variety of purposes. In a competitive health research market, prioritizing the perspectives of consumers directly affected by certain conditions has wider implications for public health and public resource distribution. Certain conditions affecting some consumer/citizens currently get lots of research attention and resources while other (more common conditions) get little (Ioannidis, 2016).

\section{TYPOLOGIES OF PPI}

Different models of PPI carry distinctive and sometimes contradictory assumptions about the types of public to be involved, the knowledge those publics might bring to bear, and their degree of involvement in decision-making processes. Ives et al. (2013) in questioning, "whether the concept/practice of PPI is internally coherent" (p. 181), identify two broad sets of motivations for PPI. The first is a pragmatic and outcome orientated type of PPI which positively impacts on the "quality of research processes and outputs, and promotes more reliable, relevant research" (p. 181). The second is a more ideological, rights-based type of PPI which, "draws on broader social and ethical narratives around democratic representation, transparency, accountability, responsibility and the redressing of power imbalances," (p. 181). Ives et al. set up a dichotomy between a pragmatic, transactionbased model, and a more ideological, process-orientated model, arguing that if lay people become too expert at carrying out research they will jeopardize their "genuine" lay status. The implication is that public involvement should be confined to funding decisions, prioritization of research agendas, research governance, and ethical review, where "layness" is the required asset.

Knaapen and Lehoux (2016) similarly find confusion and contradiction in the underlying principles guiding PPI in clinical standard setting. They categorize arguments in favor of PPI into three main types. These are first, a theoretical case for citizen participation premised on notions of individual rights, civic responsibility, social justice, and political accountability (a democratic voice model of PPI); second, a consumerist argument for involving autonomous consumers in personalizing clinical care (a consumer choice model); and third, an argument which claims that experiential knowledge from those affected improves health research (a lay expertise model). There is a clear overlap across these three types, but also, each has a somewhat different conception of the use and utility of PPI, which at times, pull the constituent PPI actors in opposite directions. For example, consider the impossibility of trying to reconcile a consumer choice model of PPI with the altruism and surrendering of choice required of those being asked to take part in randomized controlled trials as research subjects. Ethical standards dictate that patients and clinicians should not consent to randomization unless there is uncertainty about whether any of the treatment options in a trial offers greater harm or benefit than any other. However, explaining the uncertainty principle is challenging (Madden and Morley, 2016) and there is some evidence of "therapeutic misconception," where, despite explanation, participants maintain the view that taking part in research is to benefit them directly rather than to test or compare treatment methods and resolve uncertainty (Appelbaum et al., 1987). As Dean (2017) points out, the empowered self-interest of the neoliberal consumer-citizen is somewhat at odds with the, "other-oriented, reasoning-citizen of deliberative democracy," (p. 2). 
This tension is something that Dean (2017) attempts to address by proposing a new typology of public participation (involvement) in policy decisions. In this model, Dean identifies two intersecting dimensions that underpin all PPI activity, a dimension of sociality and a dimension of negotiability. The sociality dimension is the extent to which PPI activities are agonistic or solidaristic. Agonistic participation is “...conflictual with individuals and groups predominantly concerned with promoting and defending their own interests and values against other participants," (p. 4). Solidaristic participation is where, "participants view themselves as interdependent members of a social collective and participation is oriented towards collective ends and the common good," (p. 5). In negotiated participatory spaces, the conditions of participation are determined by the participants themselves, as part of the process. In prescribed participatory spaces, issues of who participates and how they do so, "are determined outside of the space (perhaps by the commissioning organisation, perhaps by circumstance) and imposed upon the participants, who thus have little scope to determine the conditions of their participation," (p. 5).

For Dean, different modes of participation are reflective of changing notions of the form and function of the state, combined with, "characteristic participatory practices and conceptions of the citizen" (p. 14). Dean does not propose this model as a schema for characterizing all forms of participation, but the notion of dimensionality is useful as a means for identifying specific tropes, processes, and practices that might play out across PPI activity. Dean's dimensional approach enables us to make sense of the inherent tensions between consumer choice models of PPI versus lay expertise and democratic models, allowing us to begin to understand how these contradictory and indeed conflictual models can exist and persist in the same field at the same time. For example, the JLA approach moves beyond the aggregation of individual/patient concerns to include the prioritization of research through deliberation but within a narrow topic focus and only from the perspective of those directly affected (and relevant health professionals). Wider societal perspectives, including inequities in what attracts most research attention and how public resources are allocated among competing interests are outside its scope (Cullum et al., 2016).

\section{APPLYING TYPES OF PPI}

Limited engagement with its own history and the skills, experience and evidence-base outside the narrow disciplinary boundaries of health sciences fuels a sense that mainstream NHS and NIHR PPI initiatives constantly reinvent the wheel (INVOLVE, 2015a). For example, social movements, charities, and non-governmental organizations have invented and experimented with a range of participatory mechanisms (including user-controlled research and service provision) to bring together citizens and experts in new forms of cooperative inquiry. These have often been critical of established policy and political contexts and have employed a range of participatory techniques intended to strengthen civil society while also problematizing how participation works (e.g., Cooke and Kothari, 2001). In this context, PPI can be seen as a field of solidaristic, non-governmental public-spirited experimentation, much of it located in the memories and documentary traces of citizens and activists whose attempts at an informal type of PPI often get overlooked and "forgotten" within formal, more individualistic PPI processes.

Formal PPI policy initiatives proliferate alongside a huge growth in the amount of health research funded and published, although, "there is little to suggest increased outputs have led to real improvements in patient care" (Heneghan et al., 2016). Despite the rise of the evidence-based medicine movement, Maynard (2012) argues that UK health care is still (and perhaps more than ever) an arena of faith-based policy making. For Bambra (2013), "politics has primacy" in policy making regardless of the rhetorical emphasis on evidence. Yet, thorny issues of politics and power are backgrounded in the resulting dominant individualistic, politely agonistic forms of participation, meaning that insufficient attention is paid to connections between clinical (bio-medical) and public (social) health contexts.

\section{ARNSTEIN REDUX?}

Arnstein's (Arnstein, 1969) much-cited ladder of participation clearly equates participation (involvement) with the power of citizens to make decisions. It has been both influential and controversial (see Tritter and McCallum, 2006). Dean (2017) characterizes Arnstein as having an activist's view of participation, as, "insurgency against government power" and indeed as a redistribution of power (p. 2). Certainly, Arnstein is clear that there is a critical difference between going through the empty ritual of participation/involvement and having the real power needed to affect the outcome of the process. Participation without redistribution of power is an empty and frustrating process, "it allows the powerholders to claim that all sides were considered, but makes it possible for only some of those sides to benefit. It maintains the status quo..." (p. 217). The political implications of contemporary PPI, when and if they are discussed, tend to be couched in "moral" rather than redistributive terms (Wilson et al., 2015). Arnstein's view resonates with the hubristic statement from NHS England above and with Wilson et al's (Wilson et al., 2015) findings that patients involved in health research are most often involved in steering committees with uncertain powers to steer or in reviewing participant information leaflets.

This is not to say Arnstein's work is without criticism. She was the first to point out why her ladder, "obviously... a simplification" (p. 217), should be used to generate discussion rather than as an off the peg "tool” or model. However, Arnstein's depiction does offer a contra view to current contexts, where public policy issues are increasingly presented as arising from aggregated individual choices made in a marketplace rather than the outcome of structural or political arrangements. Formal NHS PPI processes draw from an under-socialized view of a consumerist subject constituted within a transactional and individualistic participatory paradigm, which leaves matters of public value as free floating arbitrary ideas to be determined by individual choice. The potential for the conflictual nature of democratic politics is underplayed, as the nature of the public good is reduced to a matter of personal preference and individual experience. In 
this context, PPI "experts by experience" are in danger of being reduced to another commodity, as an opportunity for professionals to consume affective individual testimony without the need to engage with wider publics or more contextualized forms of research. Narratives of experience are structured, performative, means of understanding, and persuasion, not an unproblematic means of transparent access to truth. Those asked to narrate their experience are subject to the quest for particular forms of expert, but not too expert, experience (Martin, 2008; Thompson et al., 2012; Snow, 2016).

\section{CONCLUSION}

It is in this context that we assert that PPI operates as an empty signifier, intermittently populated with whatever policy ideas of citizen engagement are a la mode (Stewart, 2012). Maynard (2012) depicts contemporary health policy making as Nirvania, a land of faith inhabited by zombies and unicorns. This draws on Evans et al.s (Evans et al., 1994) characterization of zombie ideas as, "intellectually dead but...never buried," because they, "offer a simple and intuitively appealing 'solution' to a complex and urgent policy problem," (p. 1). Applying Maynard's (Maynard, 2012) Nirvanian terminology, formal PPI can be seen as a ghastly composite of a zombie policy that continually pops up, offering (but never providing) a solution to purported deficits in democratic engagement, despite being useless in the last policy round, and a unicorn policy, a mythical beast, prevalent, and much discussed but never discovered in replicable form in any health-care system. This zombie/unicorn hybrid creates PPI as a form of busywork in which the politics of social movements are entirely displaced by technocratic discourses of managerialism.

Meanwhile, patients are becoming competitive consumers for public and private funds as neoliberal policy delegates ever more of the state's functions to capital, transforming the value of the public good to the benefit of private individuals. PPI is part of a

\section{REFERENCES}

Appelbaum, P., Roth, L., Lidz, C., Benson, P., and Winslade, W. (1987). False hopes and best data: consent to research and the therapeutic misconception. Hastings Cent. Rep. 17, 20-24. doi:10.2307/3562038

Arnstein, S. R. (1969). A ladder of citizen participation. J. Am. Inst. Plann. 35, 216-224. doi:10.1080/01944366908977225

Bambra, C. (2013). The primacy of politics: the rise and fall of evidence-based public health policy? J. Public Health 35, 486-487. doi:10.1093/pubmed/fdt113

Berwick, D. (2013). A Promise to Learn - A Commitment to Act: Improving the Safety of Patients in England. London: Department of Health.

Brett, J., Staniszewska, S., Mockford, C., Seers, K., Herron-Marx, S., and Bayliss, H. (2010). The PIRICOM Study: A Systematic Review of the Conceptualisation, Measurement, Impact and Outcomes of Patients and Public Involvement in Health and Social Care Research. Warwick: University of Warwick.

Cooke, B., and Kothari, U. (2001). Participation: The New Tyranny? London: Zed Books.

Crowe, S., and Ceinwen, G. (2016). Making patient relevant clinical research a reality. BMJ 355, i6627. doi:10.1136/bmj.i6627

Cullum, N., Buckley, H., Dumville, J., Hall, J., Lamb, K., Madden, M., et al. (2016). Wounds research for patient benefit: a 5-year programme of research. Programme Grants Appl. Res. 4, 303. doi:10.3310/pgfar04130

Dean, R. (2017). Beyond radicalism and resignation: the competing logics for public participation in policy decisions. Policy Polit. 45, 213-230. doi:10.1332/ 030557316X14531466517034 wider politics of knowledge in which patient groups, clinicians and universities are co-opted into a corporatized health research agenda (Gabe et al., 2012). Involvement should be about populations engaging in the decisions that impact their lives, identifying opportunities and strategies for action. Being "critically involved" requires acknowledging processes of situated contestation rather than epistemic authority, identifying varieties of publics and the contingency and complexity of the construction of evidence. The ongoing narrow technocratic co-option of PPI is not grounds for yet more cynicism but for a renewed skepticism that actively seeks evidence and understanding of the fields of power within which health equity and meaningful participation for transformative health and social change lie. For example, it might be useful for patients and the public interested in health research to know more about the difficulty of producing health research which addresses meaningful clinical and public health outcomes. Despite the technocratic ratcheting up of expectations and claims for impact, many experts by experience of research acknowledge that most clinical research is not useful and is in need of reform (Ioannidis, 2016), that the EBM "quality mark" has been misappropriated by vested interests (Greenhalgh et al., 2014) and that while the UK has been recognized as a global leader in research and policy on health inequalities, these inequalities continue to widen leaving some researchers feeling that all they are doing is counting the bodies (Garthwaite et al., 2016). PPI offers the opportunity to help address some or all of these failings, but not if context and history continue to be ignored and there is failure to properly evaluate because we are off chasing the Nirvanian zombie/unicorns that spring from the landscape of NHS redisorganization (c.f., Oxman et al., 2005).

\section{AUTHOR CONTRIBUTIONS}

Both authors have contributed equally to the production of this manuscript.

Department of Health Research and Development Directorate (2006). Best Research for Best Health. A New National Health Research Strategy. Available at: https://www.gov.uk/government/uploads/system/uploads/attachment_data/ file/568772/dh_4127152_v2.pdf

Evans, R., Barer, M., Stoddart, G., and Bhatia, V. (1994). Who Are the Zombie Masters and What Do They Want? BC, Canada: University of British Columbia.

Francis, R. (2013). Report of the Mid Staffordshire NHS Foundation Trust Public Inquiry. London: Crown Copyright.

Frankfurt, H. (2005). On Bullshit. Oxfordshire: Princeton University Press.

Fredrikkson, M., and Tritter, J. (2017). Disentangling patient and public involvement in healthcare decisions: why the difference matters. Sociology of Health and Illness. 39, 95-111. doi:10.1111/1467-9566.12483

Gabe, J., Chamberlain, K., Norris, P., Dew, K., Madden, H., and Hodgetts, D. (2012). The debate about the funding of Herceptin: a case study of 'countervailing powers'. Soc. Sci. Med. 75, 2353-2361. doi:10.1016/j.socscimed.2012.09.009

Garthwaite, K., Smith, K. E., Bambra, C., and Pearce, J. (2016). Desperately seeking reductions in health inequalities: perspectives of UK researchers on past, present and future directions in health inequalities research. Sociol. Health Illn. 38 , 459-478. doi:10.1111/1467-9566.12374

Godlee, F. (2015). Too much medicine. BMJ 350, h1217. doi:10.1136/bmj.h1217

Gradinger, F., Britten, N., Wyatt, K., Froggatt, K., Gibson, A., Jacoby, A., et al. (2015). Values associated with public involvement in health and social care research: a narrative review. Health Expect. 18, 661-675. doi:10.1111/hex.12158

Greenhalgh, T., Howick, J., and Maskrey, N. (2014). Evidence based medicine: a movement in crisis? BMJ 348, g3725. doi:10.1136/bmj.g3725 
Heneghan, C., Goldacre, B., and Mahtani, K. (2017). Why clinical trial outcomes fail to translate into benefits for patients. Trials 18, 122. doi:10.1186/ s13063-017-1870-2

Heneghan, C., Mahtani, K., Goldacre, B., Godlee, F., Macdonald, H., and Snow, R. (2016). EBM Manifesto. Available at: http://evidencelive.org/manifesto/V1.5

INVOLVE. (2014). NIHR Senior Investigators: Leaders for Patient and Public Involvement in Research. Eastleigh: INVOLVE.

INVOLVE. (2015a). What Is Public Involvement in Research? Available at: http:// www.invo.org.uk/find-out-more/what-is-public-involvement-in-research-2

INVOLVE. (2015b). Going the Extra Mile: Improving the Nation's Health and Wellbeing through Public Involvement in Research. Eastleigh: INVOLVE.

Ioannidis, J. (2016). Why most clinical research is not useful. PLoS Med 13, e1002049.

Ives, J., Damery, S., and Redwod, S. (2013). PPI, paradoxes and Plato: who's sailing the ship? J. Med. Ethics 39, 181-185. doi:10.1136/medethics-2011100150

Knaapen, L., and Lehoux, P. (2016). Three conceptual models of patient and public involvement in standard-setting: from abstract principles to complex practice. Sci. Cult. 25, 239-263. doi:10.1080/09505431.2015.1125875

Madden, M., and Morley, R. (2016). Exploring the challenge of health research priority setting in partnership: reflections on the methodology used by the James Lind Alliance Pressure Ulcer Priority Setting Partnership. Res. Involvement Engagement 2, 12. doi:10.1186/s40900-016-0026-y

Martin, G. (2008). 'Ordinary people only': knowledge, representativeness, and the publics of public participation in healthcare. Sociol. Health Illn. 30, 35-54. doi:10.1111/j.1467-9566.2007.01027.x

Maynard, A. (2012). The Maynard doctrine: the chronicles of Nirvania, home of unicorns and zombies. Health Policy Insight. Available at: http://www.healthpolicyinsight.com/?q=node/1433

McGoey, L. (2012). Strategic unknowns: towards a sociology of ignorance. Econ. Soc. 41, 1-16. doi:10.1080/03085147.2011.637330

National Institute for Health Research. (2015). Patient and Public Involvement. Available at: https://www.nihr.ac.uk/patients-and-public/

NHS England. (2015). About NHS England. Available at: https://data.england.nhs. uk/organization/about/nhs-england

NHS Health Research Authority. (2013). Strategy for Public Involvement. Available at: http://www.hra.nhs.uk/documents/2013/10/hra-public-involvement-strategycirculation-september-2013.pdf

Norris, P. (2011). Democratic Deficit: Critical Citizens Revisited. Cambridge: Cambridge University Press.

Ocloo, J., and Fulop, N. (2011). Developing a 'critical' approach to patient and public involvement in patient safety in the NHS: learning lessons from other parts of the public sector? Health Expect. 15, 424-432. doi:10.1111/j.1369-7625.2011.00695.x

Oxman, A., Sackett, D., Chalmers, I., and Prescott, T. (2005). A surrealistic mega-analysis of redisorganization theories Journal of the Royal. Soc. Med. 98, 563-568. doi:10.1258/jrsm.98.12.563

Petersen, A., and Lupton, D. (1996). The New Public Health: Health and Self in the Age of Risk. London: SAGE.

Snow, R. (2016). What makes a real patient? BMJ Blogs. Available at: http://blogs. bmj.com/bmj/2016/07/19/rosamund-snow-what-makes-a-real-patient

Stewart, E. (2012). Governance, Participation and Avoidance: Everyday Public Involvement in the Scottish NHS. Edinburgh: University of Edinburgh.

Taylor, P. (2007). "The lay contribution to public health," in Public Health for the 21st Century: Policy, Participation and Practice, 2nd edn, eds J. Orme, M. Grey, T. Harrison, J. Powell, and P. Taylor (Berkshire: Open University Press/ McGraw Hill Education), 100-101.

Thompson, J., Bissell, P., Cooper, C., Armitage, C., and Barber, R. (2012). Credibility and the 'professionalized' lay expert: reflections on the dilemmas and opportunities of public involvement in health research. Health 16, 602-618. doi:10.1177/1363459312441008

Tritter, J., and McCallum, A. (2006). The snakes and ladders of user involvement: moving beyond Arnstein. Health Policy 76, 156-168. doi:10.1016/j. healthpol.2005.05.008

Wehling, P., Viehöver, W., and Koenen, S. (2015). The Public Shaping of Medical Research: Patient Associations, Health Movements and Biomedicine. Abingdon Oxon: Routledge.

Whitfield, D. (2012). In Place of Austerity: Reconstructing the Economy, State and Public Services. Nottingham: Spokesman.

Wilson, P., Mathie, E., Keenan, J., McNeilly, E., Goodman, C., Howe, A., et al. (2015). ReseArch with patient and public invOlvement: a realisT evaluation the RAPPORT study. Health Serv. Deliv. Res. 3, 38. doi:10.3310/hsdr03380

Conflict of Interest Statement: The authors declare that the research was conducted in the absence of any commercial or financial relationships that could be construed as a potential conflict of interest.

Copyright (c) 2017 Madden and Speed. This is an open-access article distributed under the terms of the Creative Commons Attribution License (CC BY). The use, distribution or reproduction in other forums is permitted, provided the original author(s) or licensor are credited and that the original publication in this journal is cited, in accordance with accepted academic practice. No use, distribution or reproduction is permitted which does not comply with these terms. 